\title{
Development and Simulation of 39 DOF Vehicle Model
}

\author{
Adem Tunçdamar ${ }^{1 *}$ \\ 1* Turkish Aerospace Industries, Ankara, Turkey, (ORCID: 0000-0001-7123-3942), ademtuncdamarr@gmail.com
}

(1st International Conference on Applied Engineering and Natural Sciences ICAENS 2021, November 1-3, 2021)

(DOI: 10.31590/ejosat.1010815)

ATIF/REFERENCE: Tunçdamar, A. (2021). Development and Simulation of 39 DOF Vehicle Model. European Journal of Science and Technology, (28), 743-752.

\begin{abstract}
In this study, a 39 degree-of-freedom mass-spring-damper model of a vehicle was developed. The model consists of 4 parts: wheels and suspensions, vehicle body, seats and passengers. A human model with 7 degrees of freedom was used to model the passengers. Equations of motion were obtained by drawing the free body diagram of each part. In order to solve the obtained equations of motion numerically, a model was created in the Simulink environment. To verify the accuracy of the outputs from the Simulink model, the script was written using the Python programming language. The developed model was tested by applying a road profile. Outputs from the Simulink model and test script are in agreement with each other and with the literature. Thanks to this study, the situations that affect passenger and driving comfort during vehicle design will be examined in detail with less experimentation.
\end{abstract}

Keywords: Vehicle model, Simulink, Mathematical modelling, Passenger, 39 DOF.

\section{DOF Araç Modelinin Geliştirilmesi ve Simülasyonu}

$\ddot{O} \mathbf{z}$

Bu çalışmada bir aracın 39 serbestlik dereceli kütle-yay-damper modeli geliştirilmiştir. Model; tekerlek ve süspansiyonlar, araç gövdesi, koltuklar ve yolcular olmak üzere 4 kısımdan oluşmaktadır. Yolcuları modellemek için 7 serbestlik dereceli bir insan modeli kullanılmıştır. Sistemi betimleyen hareket denklemleri her bir cismin serbest cisim diyagramı çizilerek elde edilmiştir. Elde edilen hareket denklemlerini sayısal olarak çözmek için Simulink modeli oluşturulmuştur. Simulink modelinden alınan çıktıların doğruluğunu teyit etmek için Python programla dili kullanılarak betik yazılmıştır. Geliştirilen model bir yol profilinde test edilmiştir. Simulink ve test betiğinden alınan çıktılar birbiriyle ve literatürle uyum içerisindedir. Bu çalışma sayesinde araç tasarımı sırasında yolcu ve sürüş konforunu etkileyen durumlar daha az deney yaparak, daha ucuz ve detaylı bir şekilde incelenebilecektir.

Anahtar Kelimeler: Araç modeli, Simulink, Matematiksel modelleme, Yolcu, 39 DOF

\footnotetext{
${ }^{*}$ Corresponding Author: ademtuncdamarr@gmail.com
} 


\section{Introduction}

Today, millions of automobiles are produced in hundreds of factories. The automobiles produced must meet the minimum safety requirements, meet the demands of the customer and be designed in accordance with the legal rules regulated by the laws. Mathematical models are used to check that the design requirements are met, to examine the effects of variable elements on the behaviour of the vehicle, to have preliminary information about the performance of the design before it goes into production, and for many different purposes. The most common mathematical modelling method used to predict the dynamical behaviour of the designed automobile against external factors (e.g. road profile) is the mass-spring-damper simulation. In this method, it is assumed that the elements that make up the vehicle are rigid elements with a mass value, spring coefficient and damping coefficient. Mass-spring-damper vehicle models are divided into 3 in scope and complexity:

- Quarter vehicle models

- Half vehicle models

- Full vehicle models

In quarter vehicle models, it is assumed that the vehicle body consists of a combination of mass, spring and damper that only shifts up and down. The vehicle cannot rotate around any axis. Quarter vehicle models are the narrowest in scope, but the low computation time due to their simplicity makes these models effective in simple applications. Figure 1 shows a sample quarter car model (Hendrowati, 2012).
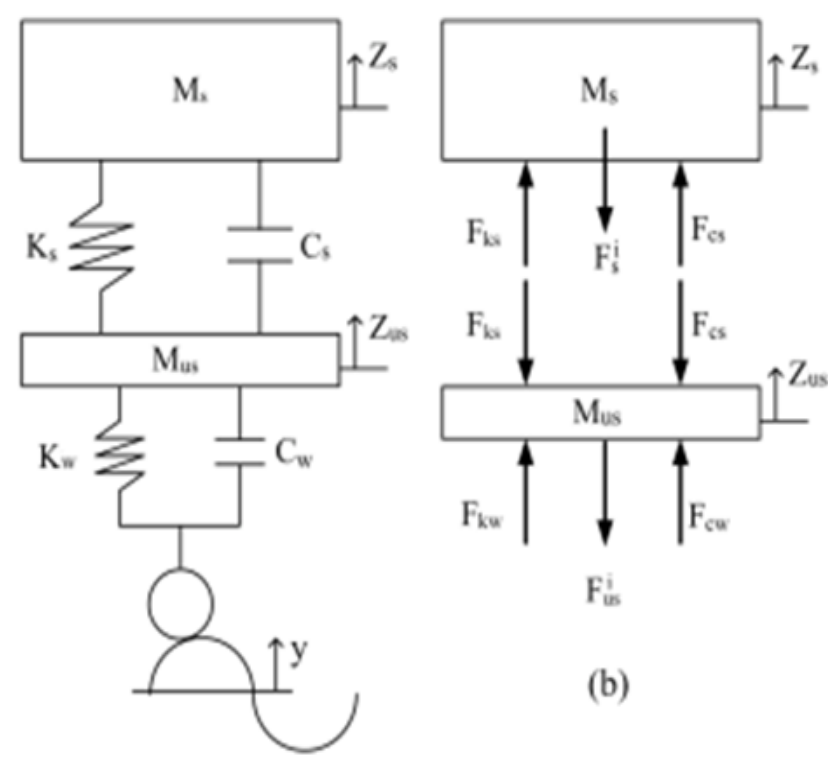

(b)

\section{Figure 1 An example of a quarter vehicle model}

If it is desired to model the pitch movement and pitching moment around the center of mass as well as the up-down translational movement of the vehicle body, half-vehicle models are used. Half vehicle models can be thought of as a system consisting of two wheels and a body, which is obtained simply by looking at the right or left profile of the vehicle. An exemplary half-car model is given in Figure 2 (Goga, 2012).

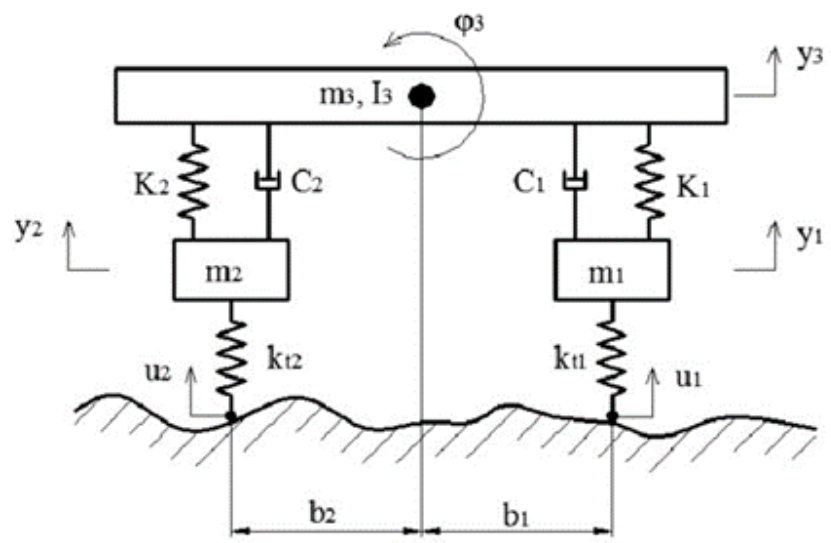

Figure 2 An example of a half vehicle model

If the up-down translational motion, pitch motion and pitching moment, roll motion and rolling moment are to be calculated simultaneously, full vehicle models should be used. Full vehicle models basically consist of 4 wheels and body. Seats on more advanced full-vehicle models, non-linear human models, etc. There may be additional parts such as Figure 3 shows the complete vehicle model consisting of 4 wheels, vehicle body and 1 seat (Meng, 2014).

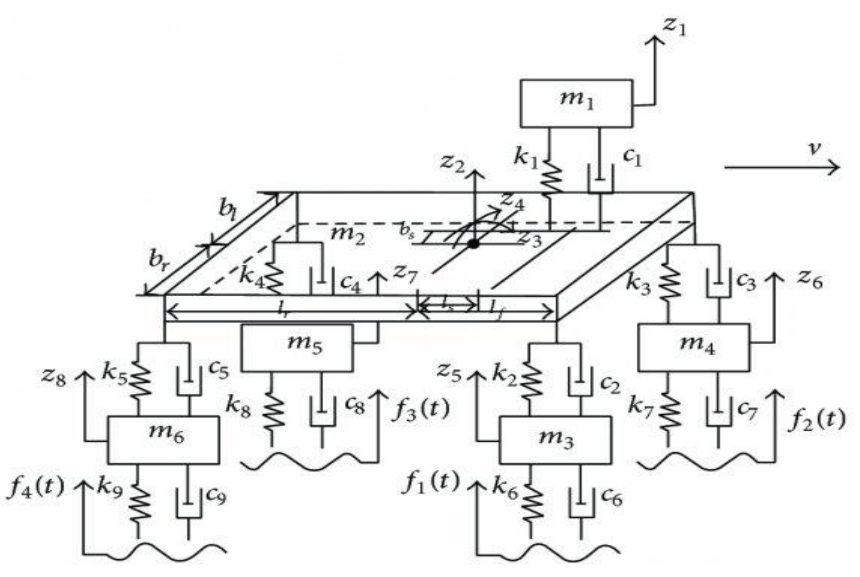

Figure 3 An example of a full vehicle model

In mass-spring-damper models, the spring and damping coefficients can generally be considered constant. This is acceptable for small displacements, but non-linear models should be used for large displacements. For nonlinear spring elements, Hooke's law (Equation 1) does not apply, and the force is usually expressed as a third-order polynomial of displacement (Equation 2).

$$
\begin{gathered}
F=k x \\
F=A x+B x^{3}
\end{gathered}
$$

Here $\mathrm{x}$ represents displacement. If the non-linear spring coefficients of the spring element used are known, an approximate linear spring coefficient can be obtained by making some assumptions (Rao, 1993). Let it be assumed that the static force $F$ causes an $\mathrm{X}$-shaped displacement on the spring. Suppose a relatively small force $\Delta F$ acts on the force $\mathrm{F}$. Due to the added force $\Delta F$, the spring deforms by $\Delta x$. If the forces acting on the spring element under these conditions open the Taylor series around the $\mathrm{x}$ equilibrium position, 


$$
F+\Delta F=F(x+\Delta x)
$$

$=F(x)+\left.\frac{d F}{d x}\right|_{x}+\left.\frac{1}{2 !} \frac{d^{2} F}{d x^{2}}\right|_{x}(\Delta x)^{2}+\left.\frac{1}{3 !} \frac{d^{3} F}{d x^{3}}\right|_{x}(\Delta x)^{3}+\cdots$

expression is obtained. Assuming that small displacements are made, expressions with larger than first-order displacements can be neglected (Equation 4).

$$
\Delta F=\left.\frac{d F}{d x}\right|_{x}(\Delta x)
$$

If the expression in Equation 4 is likened to Hooke's law given in Equation 1, the equivalent spring coefficient can be obtained (Equation 5).

$$
k_{e q}=\left.\frac{d F}{d x}\right|_{x}
$$

The equivalent spring coefficient obtained in Equation 5 can be used for small displacements, but the error will increase as the displacements increase. To minimize the error, the neglected higher order terms in the Taylor series should also be taken into account. In this study, this method was used to linearize nonlinear spring elements.

In this study, 39 degrees of freedom mass-spring-dumper model of a 4-seat and 4-passenger vehicle developed in the light of the information given above is introduced.

\section{Material and Method}

The developed model consists of 4 parts,

- Wheels and suspensions

- Vehicle body

- Seats

- Human model

The general view of the developed model is given in Figure 4.

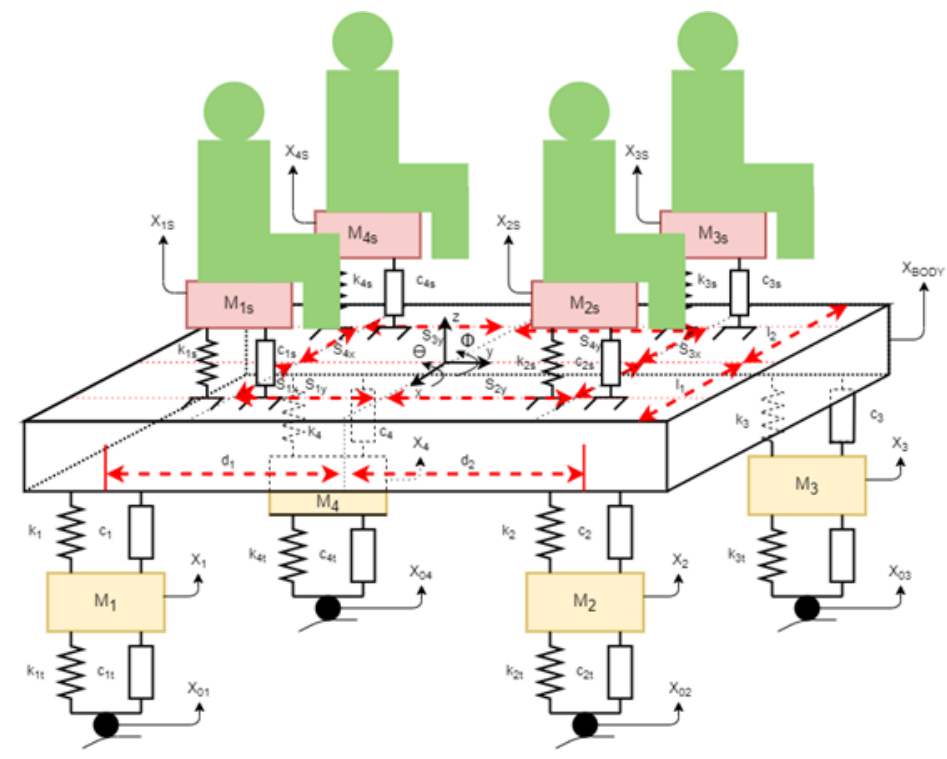

Figure 4 General view of 39 DOF vehicle model

The road profile applied to the wheels is included in the model with the input $x_{0 \text { i }}$. The springiness and damping of each wheel are expressed by $k$ it spring coefficient and $c$ it damping coefficient. The mass of the wheels and suspen sion system is represented by $m_{\mathrm{i}}$. The degree of freedom of the said mass is 1 and it can only make up-down translational motion. The suspension system consists of a spring and a damping element. The springiness of the suspension system is expressed by the spring coefficient $k_{\mathrm{a}}$, and the damping is expressed by the damping coefficient $c$ i. The $\mathrm{d}_{1}$ and $\mathrm{d}_{2}$ used in the model indicate the distance from the place where the suspension is attached to the vehicle body to the $x$-axis, and $l_{1}$ and $l_{2}$ indicate the distance from the $y$-axis. The index ' $i$ ' used in the symbols represents the wheel number.

In Figure $4, m$ as represents the masses of the seats. The springiness and damping of the seats are expressed by the spring coefficient $k$ as and the damping coefficient $c$ as. The degrees of freedom of the seats are 1 and they can only move up and down. $S_{\text {ax }}$ is the distance from the point where the seats are attached to the body to the y-axis, and $S$ ay is the distance to the x-axis. The index ' $a$ ' in the symbols indicates the seat number. The expression $m$ vehicle is the mass of the vehicle body. The vehicle body can move up and down, it can make pitch movement and roll movement.

There is one passenger on each seat. The occupants in the vehicle are represented by the human model given in Figure 5 (Palanichamy, 1978).

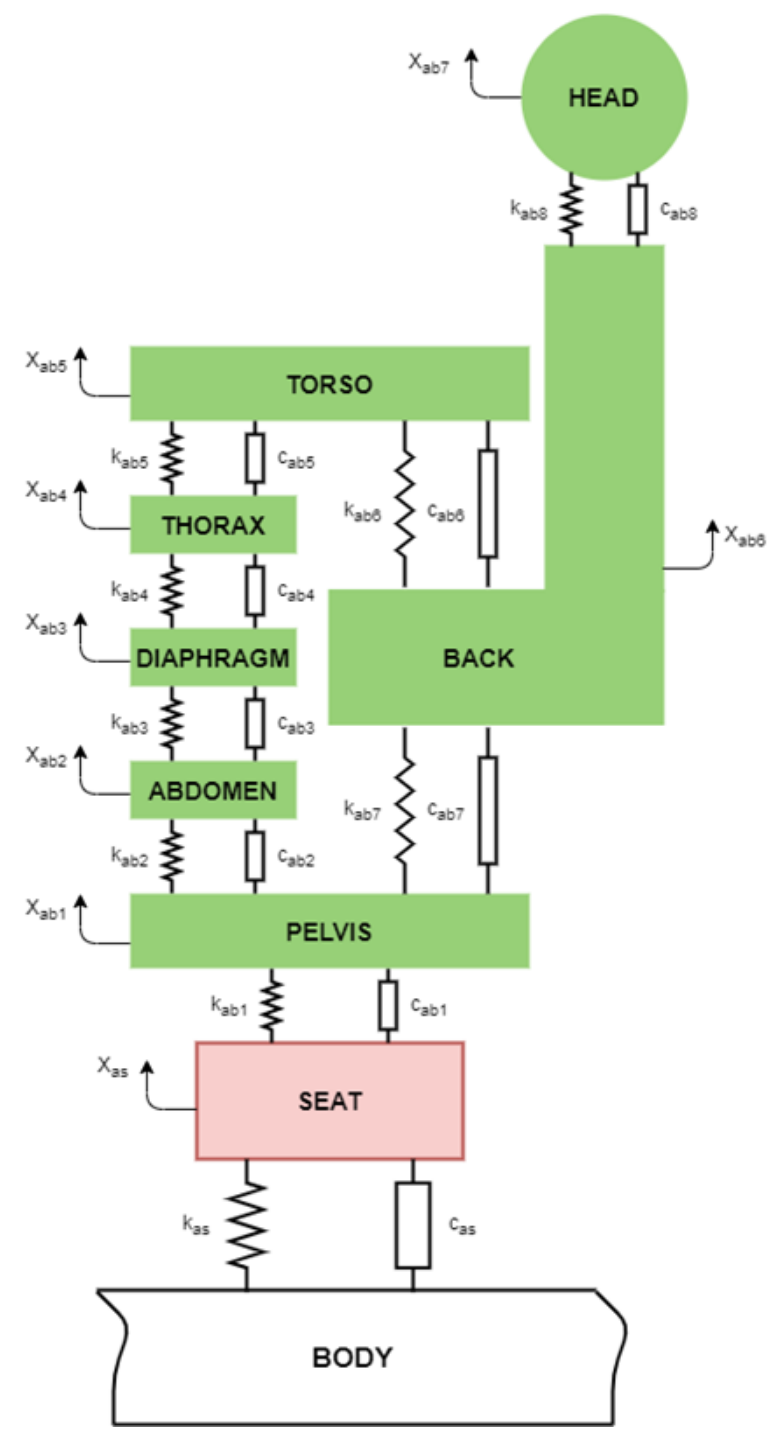

Figure 57 DOF human model 


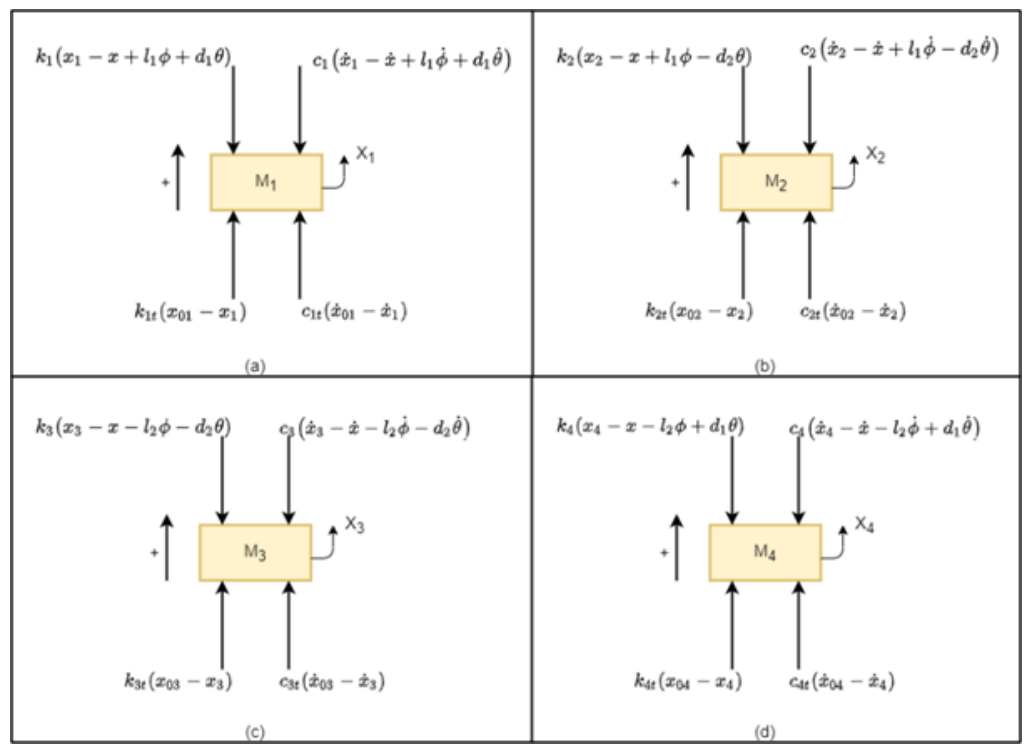

Figure 6 Free body diagrams of (a) $m 1$, (b)m2, (c)m3, (d)m 4

The human model used consists of 7 parts: pelvis, abdomen, diaphragm, thorax, torso, back and head. Each part has 1 degree of freedom and can only move up and down. Here, the index ' $a$ ' denotes the passenger and seat number. The spring and damping elements used in the model are linear, and the non-linear parts are linearized sufficiently by using Equation 5 . Equations of motion are derived by drawing a free body diagram for each element.

Free body diagrams are drawn by assuming $x_{o i}>x_{i}>x$ and $\sin \theta \approx \theta$ and $\sin \varphi \approx \varphi$ (Figure 6). If the force balance is written for $\mathrm{m}_{1}, \mathrm{~m}_{2}, \mathrm{~m}_{3}$, and $\mathrm{m}_{4}$, assuming the upward direction is positive,

$$
\begin{aligned}
\sum F_{m 1}=m_{1} \ddot{x}_{1} & \\
& =k_{1 t}\left(x_{01}-x_{1}\right)+c_{1 t}\left(\dot{x}_{01}-x \dot{x}_{1}\right) \\
& -k_{1}\left(x_{1}-x+l_{1} \varphi+d_{1} \theta\right) \\
& -c_{1}\left(\dot{x}_{1}-\dot{x}+l_{1} \dot{\varphi}+d_{1} \dot{\theta}\right)
\end{aligned}
$$

$$
\begin{aligned}
\sum F_{m 2}=m_{2} \ddot{x}_{2} & \\
& =k_{2 t}\left(x_{02}-x_{2}\right)+c_{2 t}\left(\dot{x}_{02}-\dot{x}_{2}\right) \\
& -k_{2}\left(x_{2}-x+l_{1} \varphi-d_{2} \theta\right) \\
& -c_{2}\left(\dot{x}_{2}-\dot{x}+l_{1} \dot{\varphi}-d_{2} \dot{\theta}\right)(7)
\end{aligned}
$$

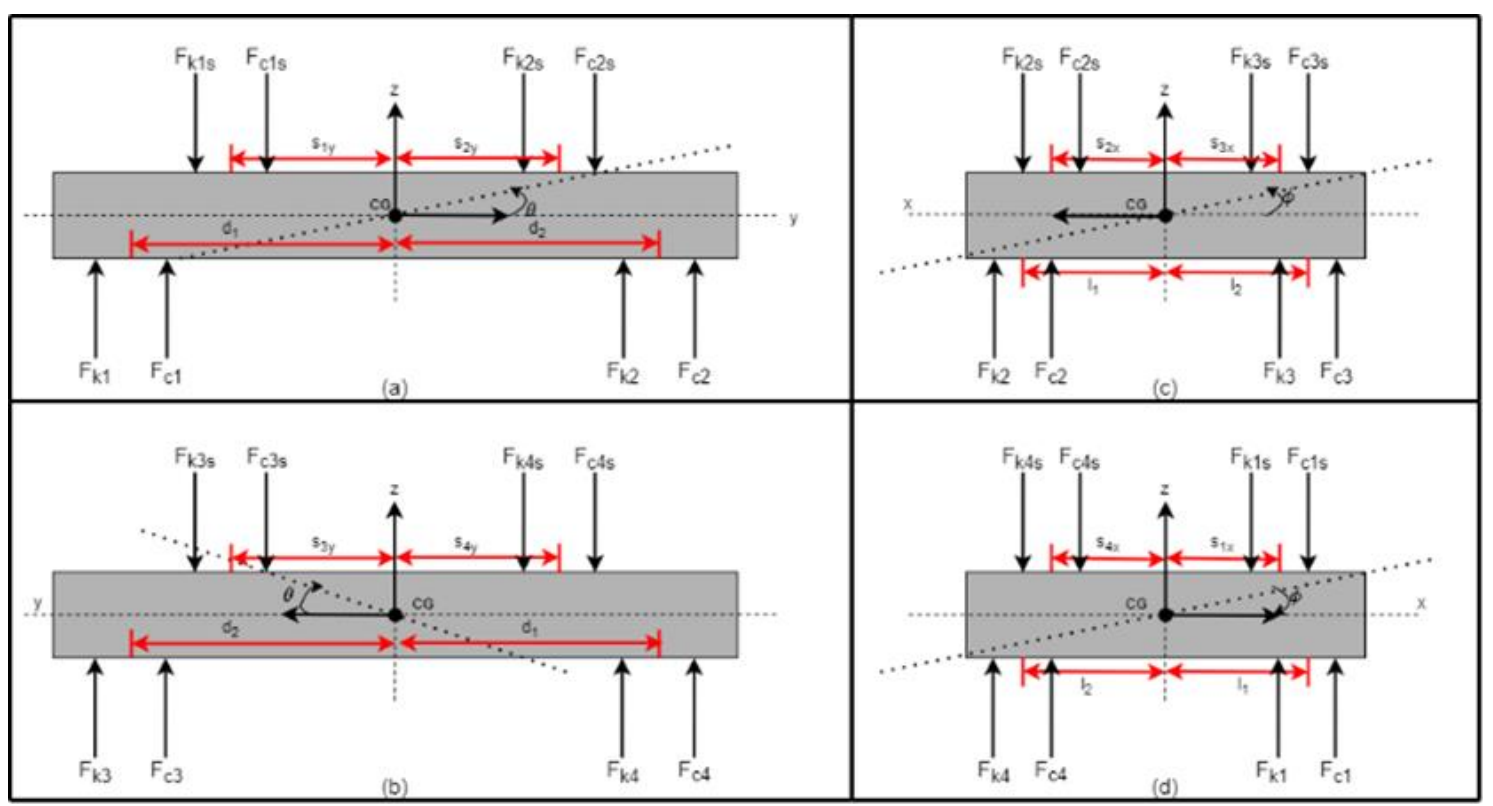

Figure 7 Free body diagrams of vehicle body (a)right side, (b)left side, (c)front side, (d)back side 


$$
\begin{aligned}
\sum F_{m 3}=m_{3} \ddot{x}_{3} & \\
& =k_{3 t}\left(x_{03}-x_{3}\right)+c_{3 t}\left(\dot{x}_{03}-\dot{x}_{3}\right) \\
& -k_{3}\left(x_{3}-x-l_{2} \varphi-d_{2} \theta\right) \\
& -c_{3}\left(\dot{x}_{3}-\dot{x}-l_{2} \dot{\varphi}-d_{2} \dot{\theta}\right)
\end{aligned}
$$

$$
\begin{aligned}
\sum F_{m 4}=m_{4} \ddot{x}_{4} & \\
& =k_{4 t}\left(x_{04}-x_{4}\right)+c_{4 t}\left(\dot{x}_{04}-\dot{x}_{4}\right) \\
& -k_{4}\left(x_{4}-x-l_{2} \varphi+d_{1} \theta\right) \\
& -c_{4}\left(\dot{x}_{4}-x-l_{2} \dot{\varphi}+d_{1} \dot{\theta}\right)
\end{aligned}
$$

The equations of motion are obtained for wheels and suspensions.

The vehicle body can perform up-down translation, pitch and roll movements. In other words, the degree of freedom is 3 . For this reason, three equations of motion are needed to model the motion of the vehicle body. These equations will be obtained by creating one force and two moment balance equations. Vehicle body and free body diagrams of vehicle body are given in Figure 7 below.

The $F_{\text {ki }}$ and $F_{\text {ci }}$ forces in the figures above refer to the spring and damper forces from the suspensions, and the $F$ kas and $F$ cas forces to the spring and damper forces from the seats. Here, ' $i$ ' and ' $a$ ' are indices, where i represents the suspension and wheel number and a represents the seat number. In addition, the lengths of $d_{1}$ and $d_{2}$ indicate the distance from the point where the suspension is attached to the body to the $\mathrm{x}$-axis, and the lengths of $l_{1}$ and $l_{2}$ indicate the distance from the y-axis. $s_{\text {ax }}$ is the distance from the point where the seats are attached to the body to the y-axis, and $s$ ay is the distance from the x-axis. Here a is the index and represents the seat number.

Figure 7 Considering, if the force and moment balances are written by assuming positive upward direction and right-hand coordinate system (for $x_{1}, x_{2}, x_{3}, x_{4}>x>$ $\left.x_{1 s}, x_{2 s}, x_{3 s}, x_{4 s}, \sin \theta \approx \theta, \sin \varphi \approx \varphi\right)$,

$$
\begin{aligned}
& \sum F_{b o d y}=m_{\text {body }} \ddot{x} \\
&=k_{1}\left(x_{1}-x+l_{1} \varphi+d_{1} \theta\right) \\
&+c_{1}\left(\dot{x}_{1}-\dot{x}+l_{1} \dot{\varphi}+d_{1} \dot{\theta}\right) \\
&+k_{2}\left(x_{2}-x+l_{1} \varphi-d_{2} \theta\right) \\
&+c_{2}\left(\dot{x}_{2}-\dot{x}+l_{1} \dot{\varphi}-d_{2} \dot{\theta}\right) \\
&+k_{3}\left(x_{3}-x-l_{2} \varphi-d_{2} \theta\right) \\
&+c_{3}\left(\dot{x}_{3}-\dot{x}-l_{2} \dot{\varphi}-d_{2} \dot{\theta}\right) \\
&+k_{4}\left(x_{4}-x-l_{2} \varphi+d_{1} \theta\right) \\
&+c_{4}\left(\dot{x}_{4}-\dot{x}-l_{2} \dot{\varphi}+d_{1} \dot{\theta}\right) \\
&-k_{1 s}\left(x-x_{1 s}-s_{1 y} \theta-s_{1 x} \varphi\right) \\
&-c_{1 s}\left(\dot{x}-\dot{x}_{1 s}-s_{1 y} \dot{\theta}-s_{1 x} \dot{\varphi}\right) \\
&-k_{2 s}\left(x-x_{2 s}+s_{2 y} \theta-s_{2 x} \varphi\right) \\
&-c_{2 s}\left(\dot{x}-\dot{x}_{2 s}+s_{2 y} \dot{\theta}-s_{2 x} \dot{\varphi}\right) \\
&-k_{3 s}\left(x-x_{3 s}+s_{3 y} \theta+s_{3 x} \varphi\right) \\
&-c_{3 s}\left(\dot{x}-\dot{x}_{3 s}+s_{3 y} \dot{\theta}+s_{3 x} \dot{\varphi}\right) \\
&-k_{4 s}\left(x-x_{4 s}-s_{4 y} \theta+s_{4 x} \varphi\right) \\
&-c_{4 s}\left(\dot{x}-\dot{x}_{4 s}-s_{4 y} \dot{\theta}+s_{4 x} \dot{\varphi}\right)(10)
\end{aligned}
$$

$$
\begin{aligned}
\sum M_{\theta}=I_{x x} \ddot{\theta} & =-\left[k_{1}\left(x_{1}-x+l_{1} \varphi+d_{1} \theta\right)\right. \\
& \left.+c_{1}\left(\dot{x}_{1}-\dot{x}+l_{1} \dot{\varphi}+d_{1} \dot{\theta}\right)\right] d_{1} \\
& +\left[k_{2}\left(x_{2}-x+l_{1} \varphi-d_{2} \theta\right)\right. \\
& \left.+c_{2}\left(\dot{x}_{2}-\dot{x}+l_{1} \dot{\varphi}-d_{2} \dot{\theta}\right)\right] d_{2} \\
& +\left[k_{3}\left(x_{3}-x-l_{2} \varphi-d_{2} \theta\right)\right. \\
& \left.+c_{3}\left(\dot{x}_{3}-\dot{x}-l_{2} \dot{\varphi}-d_{2} \dot{\theta}\right)\right] d_{2} \\
& -\left[k_{4}\left(x_{4}-x-l_{2} \varphi+d_{1} \theta\right)\right. \\
& \left.+c_{4}\left(\dot{x}_{4}-\dot{x}-l_{2} \dot{\varphi}+d_{1} \dot{\theta}\right)\right] d_{1} \\
& +\left[k_{1 s}\left(x-x_{1 s}-s_{1 y} \theta-s_{1 x} \varphi\right)\right. \\
& \left.+c_{1 s}\left(\dot{x}-\dot{x}_{1 s}-s_{1 y} \dot{\theta}-s_{1 x} \dot{\varphi}\right)\right] s_{1 y} \\
& -\left[k_{2 s}\left(x-x_{2 s}+s_{2 y} \theta-s_{2 x} \varphi\right)\right. \\
& \left.+c_{2 s}\left(\dot{x}-\dot{x}_{2 s}+s_{2 y} \dot{\theta}-s_{2 x} \dot{\varphi}\right)\right] s_{2 y} \\
& -\left[k_{3 s}\left(x-x_{3 s}+s_{3 y} \theta+s_{3 x} \varphi\right)\right. \\
& \left.+c_{3 s}\left(\dot{x}-\dot{x}_{3 s}+s_{3 y} \dot{\theta}+s_{3 x} \dot{\varphi}\right)\right] s_{3 y} \\
& +\left[k_{4 s}\left(x-x_{4 s}-s_{4 y} \theta+s_{4 x} \varphi\right)\right. \\
& \left.+c_{4 s}\left(\dot{x}-\dot{x}_{4 s}-s_{4 y} \dot{\theta}+s_{4 x} \dot{\varphi}\right)\right] s_{4 y}
\end{aligned}
$$

$$
\begin{aligned}
\sum M_{\varphi}=I_{y y} \dddot{\varphi} & =-\left[k_{1}\left(x_{1}-x+l_{1} \varphi+d_{1} \theta\right)\right. \\
& \left.+c_{1}\left(\dot{x}_{1}-\dot{x}+l_{1} \dot{\varphi}+d_{1} \dot{\theta}\right)\right] l_{1} \\
& -\left[k_{2}\left(x_{2}-x+l_{1} \varphi-d_{2} \theta\right)\right. \\
& \left.+c_{2}\left(\dot{x}_{2}-\dot{x}+l_{1} \dot{\varphi}-d_{2} \dot{\theta}\right)\right] l_{1} \\
& +\left[k_{3}\left(x_{3}-x-l_{2} \varphi-d_{2} \theta\right)\right. \\
& \left.+c_{3}\left(\dot{x}_{3}-\dot{x}-l_{2} \dot{\varphi}-d_{2} \dot{\theta}\right)\right] l_{2} \\
& +\left[k_{4}\left(x_{4}-x-l_{2} \varphi+d_{1} \theta\right)\right. \\
& \left.+c_{4}\left(\dot{x}_{4}-\dot{x}-l_{2} \dot{\varphi}+d_{1} \dot{\theta}\right)\right] l_{2} \\
& +\left[k_{1 s}\left(x-x_{1 s}-s_{1 y} \theta-s_{1 x} \varphi\right)\right. \\
& \left.+c_{1 s}\left(\dot{x}-\dot{x}_{1 s}-s_{1 y} \dot{\theta}-s_{1 x} \dot{\varphi}\right)\right] s_{1 x} \\
& +\left[k_{2 s}\left(x-x_{2 s}+s_{2 y} \theta-s_{2 x} \varphi\right)\right. \\
& \left.+c_{2 s}\left(\dot{x}-\dot{x}_{2 s}+s_{2 y} \dot{\theta}-s_{2 x} \dot{\varphi}\right)\right] s_{2 x} \\
& -\left[k_{3 s}\left(x-x_{3 s}+s_{3 y} \theta+s_{3 x} \varphi\right)\right. \\
& \left.+c_{3 s}\left(\dot{x}-\dot{x}_{3 s}+s_{3 y} \dot{\theta}+s_{3 x} \dot{\varphi}\right)\right] s_{3 x} \\
& -\left[k_{4 s}\left(x-x_{4 s}-s_{4 y} \theta+s_{4 x} \varphi\right)\right. \\
& \left.+c_{4 s}\left(\dot{x}-\dot{x}_{4 s}-s_{4 y} \dot{\theta}+s_{4 x} \dot{\varphi}\right)\right] s_{4 x}
\end{aligned}
$$

The equations of motion of the vehicle body are obtained.

There are 4 seats in the developed vehicle model. The degrees of freedom of the seats are 1 and they can only move up and down. For the seats, the free body diagrams are drawn by assuming $x>x_{\text {as }}>x$ abl (Figure 8).

The $m$ as in is mass of the seats. Considering Figure 8, if the force balances are written for the right-hand coordinate system, with the upward direction being positive,

$$
\begin{aligned}
\sum F_{m 1 s}=m_{1 s} \ddot{x}_{1 s} & \\
& =k_{1 s}\left(x-x_{1 s}-s_{1 y} \theta-s_{1 x} \varphi\right) \\
& +c_{1 s}\left(\dot{x}-\dot{x}_{1 s}-s_{1 y} \dot{\theta}-s_{1 x} \dot{\varphi}\right) \\
& -k_{1 b 1}\left(x_{1 s}-x_{1 b 1}\right) \\
& -c_{1 b 1}\left(\dot{x}_{1 s}-\dot{x}_{1 b 1}\right)
\end{aligned}
$$




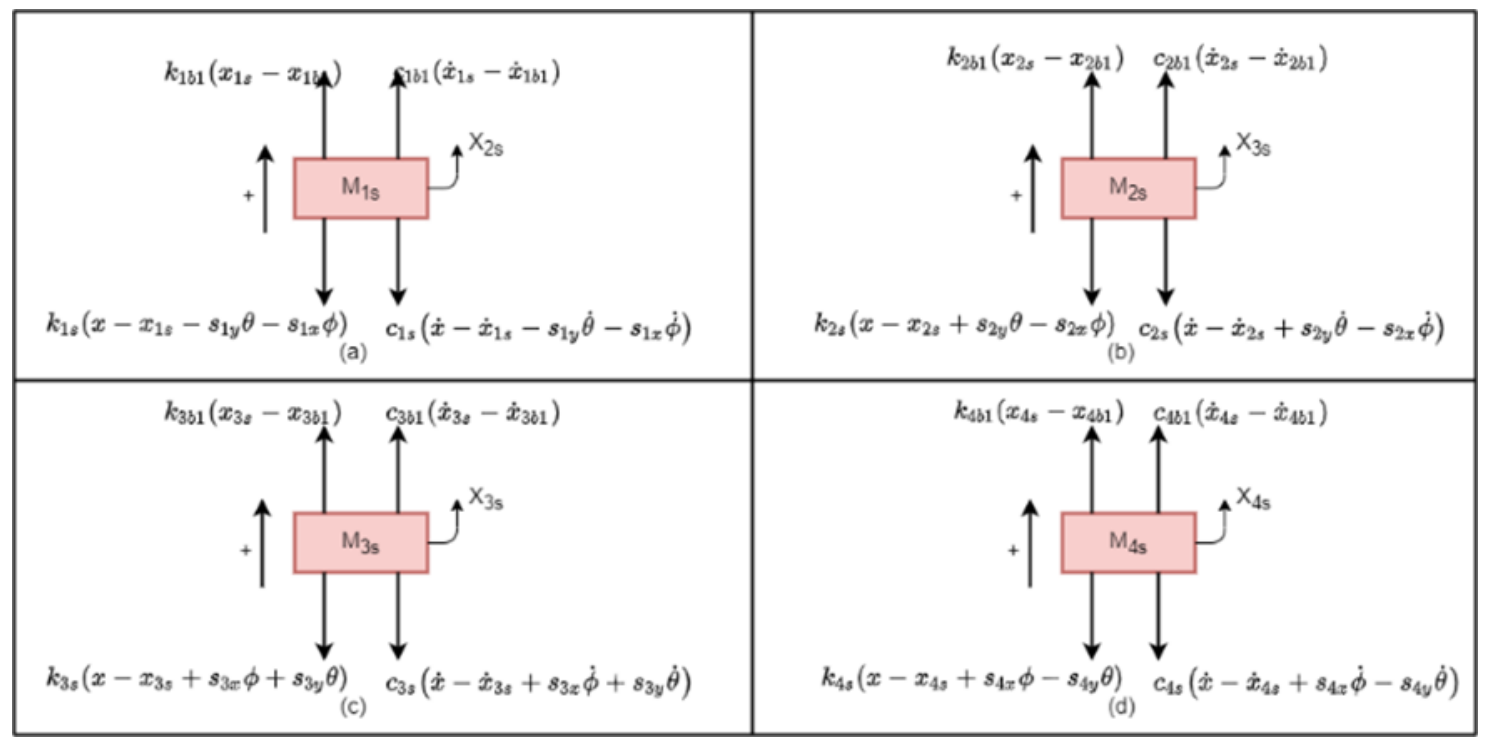

Figure 8 Figure 8 Free body diagrams of seats (a)first seat, (b)second seat, (c)third seat, (d)fourth seat

$$
\begin{aligned}
\sum F_{m 2 s}=m_{2 s} \ddot{x}_{2 s} & \\
& =k_{2 s}\left(x-x_{2 s}+s_{2 y} \theta-s_{2 x} \varphi\right) \\
& +c_{2 s}\left(\dot{x}-\dot{x}_{2 s}+s_{2 y} \dot{\theta}-s_{2 x} \dot{\varphi}\right) \\
& -k_{2 b 1}\left(x_{2 s}-x_{2 b 1}\right) \\
& -c_{2 b 1}\left(\dot{x}_{2 s}-\dot{x}_{2 b 1}\right) \quad(14) \\
\sum F_{m 3 s}=m_{3 s} \ddot{x}_{3 s} & \\
& =k_{3 s}\left(x-x_{3 s}+s_{3 y} \theta+s_{3 x} \varphi\right) \\
& +c_{3 s}\left(\dot{x}-\dot{x}_{3 s}+s_{3 y} \dot{\theta}+s_{3 x} \dot{\varphi}\right) \\
& -k_{3 b 1}\left(x_{3 s}-x_{3 b 1}\right) \\
& -c_{3 b 1}\left(\dot{x}_{3 s}-\dot{x}_{3 b 1}\right) \quad(15) \\
\sum F_{m s 4}=m_{4 s} & \ddot{x}_{4 s} \\
& =k_{4 s}\left(x-x_{4 s}-s_{4 y} \theta+s_{4 x} \varphi\right) \\
& +c_{4 s}\left(\dot{x}-\dot{x}_{4 s}-s_{4 y} \dot{\theta}+s_{4 x} \dot{\varphi}\right) \\
& -k_{4 b 1}\left(x_{4 s}-x_{4 b 1}\right) \\
& -c_{4 b 1}\left(\dot{x}_{4 s}-\dot{x}_{4 b 1}\right) \quad(16)
\end{aligned}
$$

The human model used consists of the pelvis, abdomen, diaphragm, thorax, torso, back, and head. Each of these parts has 1 degree of freedom and can only make up-down translational motion. A free body diagrams are drawn separately for each part, and the force balance equations are written by making the assumptions $\quad x_{\mathrm{as}}>x_{\mathrm{ab} 1}>x_{\mathrm{ab} 2}>x_{\mathrm{ab} 3}>x_{\mathrm{ab} 4}>x_{\mathrm{ab} 5}, \quad x_{\mathrm{ab} 6}>x_{\mathrm{ab} 5}$ and $x_{\mathrm{ab} 1}>x_{\mathrm{ab} 6}>x_{\mathrm{ab} 7}$.

$$
\begin{aligned}
\sum F_{\text {pelvis }}= & m_{\text {pelvis }} \ddot{x}_{a b 1} \\
& =k_{a b 1}\left(x_{a s}-x_{a b 1}\right)+c_{a b 1}\left(\dot{x}_{a s}-\dot{x}_{a b 1}\right) \\
& -k_{a b 2}\left(x_{a b 1}-x_{a b 2}\right) \\
& -c_{a b 2}\left(\dot{x}_{a b 1}-\dot{x}_{a b 2}\right) \\
& -k_{a b 7}\left(x_{a b 1}-x_{a b 6}\right) \\
& -c_{a b 7}\left(\dot{x}_{a b 1}-\dot{x}_{a b 6}\right)
\end{aligned}
$$

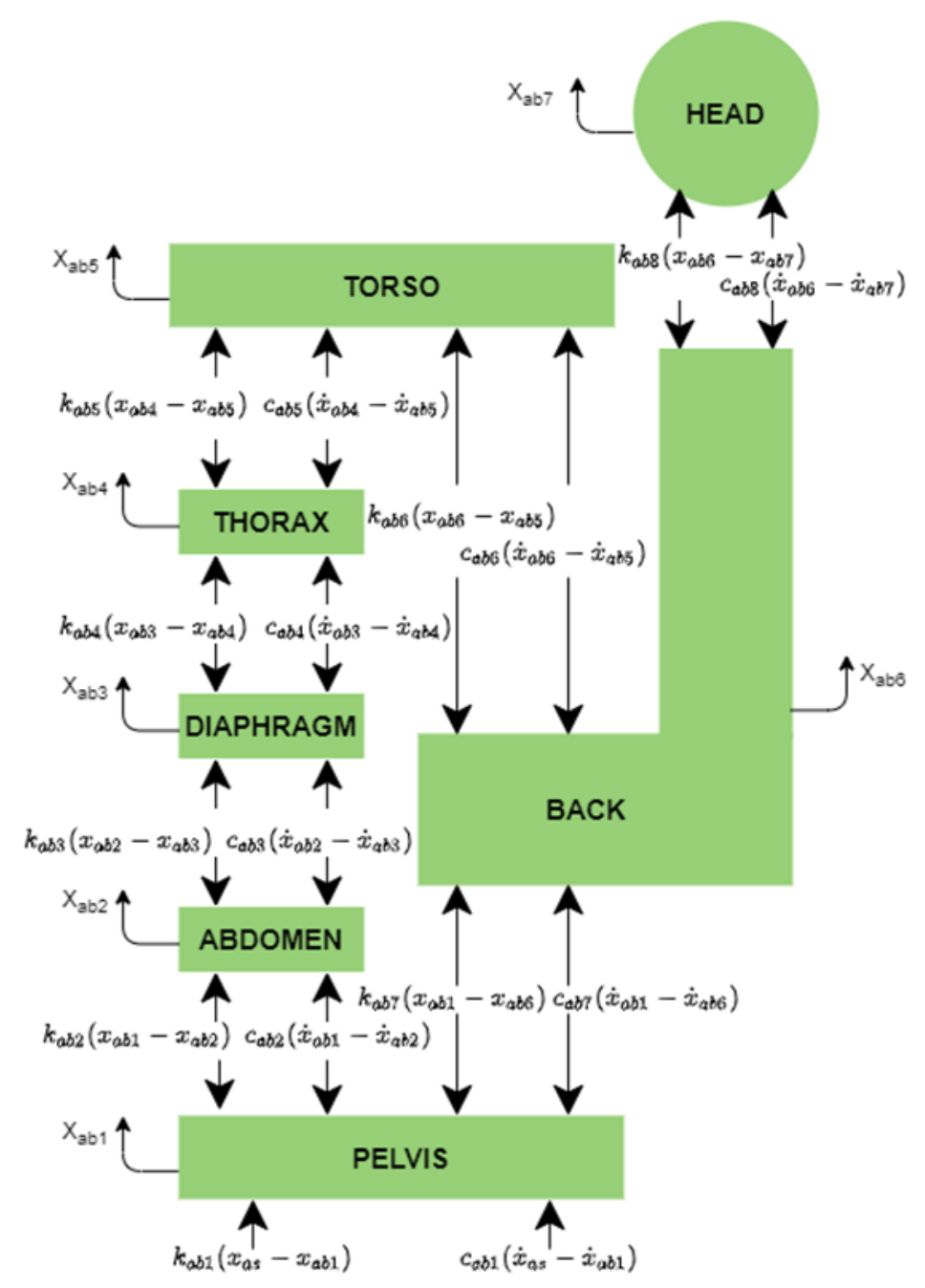

Figure 9 Free body diagram of 7 DOF human model 


$$
\begin{aligned}
\sum F_{a b d o m e n}= & m_{a b d o m e n} \ddot{x}_{a b 2} \\
& =k_{a b 2}\left(x_{a b 1}-x_{a b 2}\right) \\
& +c_{a b 2}\left(\dot{x}_{a b 1}-\dot{x}_{a b 2}\right) \\
& -k_{a b 3}\left(x_{a b 2}-x_{a b 3}\right) \\
& -c_{a b 3}\left(\dot{x}_{a b 2}-\dot{x}_{a b 3}\right)
\end{aligned}
$$

$\sum F_{\text {diaphragm }}=m_{\text {diaphragm }} \ddot{x}_{a b 3}$

$$
\begin{aligned}
& =k_{a b 3}\left(x_{a b 2}-x_{a b 3}\right) \\
& +c_{a b 3}\left(\dot{x}_{a b 2}-\dot{x}_{a b 3}\right) \\
& -k_{a b 4}\left(x_{a b 3}-x_{a b 4}\right) \\
& -c_{a b 4}\left(\dot{x}_{a b 3}-\dot{x}_{a b 4}\right)
\end{aligned}
$$

$\sum F_{\text {thorax }}=m_{\text {thorax }} \ddot{x}_{a b 4}$

$=k_{a b 4}\left(x_{a b 3}-x_{a b 4}\right)$

$+c_{a b 4}\left(\dot{x}_{a b 3}-\dot{x}_{a b 4}\right)$

$-k_{a b 5}\left(x_{a b 4}-x_{a b 5}\right)$

$-c_{a b 5}\left(\dot{x}_{a b 4}-\dot{x}_{a b 5}\right)$

$\sum F_{\text {torso }}=m_{\text {torso }} \ddot{x}_{a b 5}$

$$
\begin{aligned}
& =k_{a b 5}\left(x_{a b 4}-x_{a b 5}\right) \\
& +c_{a b 5}\left(\dot{x}_{a b 4}-\dot{x}_{a b 5}\right) \\
& +k_{a b 6}\left(x_{a b 6}-x_{a b 5}\right) \\
& +c_{a b 6}\left(\dot{x}_{a b 6}-\dot{x}_{a b 5}\right)
\end{aligned}
$$

$\sum F_{b a c k}=m_{b a c k} \ddot{x}_{a b 6}$

$$
\begin{aligned}
& =k_{a b 7}\left(x_{a b 1}-x_{a b 6}\right) \\
& +c_{a b 7}\left(\dot{x}_{a b 1}-\dot{x}_{a b 6}\right) \\
& -k_{a b 6}\left(x_{a b 6}-x_{a b 5}\right) \\
& -c_{a b 6}\left(\dot{x}_{a b 6}-\dot{x}_{a b 5}\right) \\
& -k_{a b 8}\left(x_{a b 6}-x_{a b 7}\right) \\
& -c_{a b 8}\left(\dot{x}_{a b 6}-\dot{x}_{a b 7}\right)
\end{aligned}
$$

$\sum F_{\text {head }}=m_{\text {head }} \ddot{x}_{a b 7}$

$$
\begin{aligned}
& =k_{a b 8}\left(x_{a b 6}-x_{a b 7}\right) \\
& +c_{a b 8}\left(\dot{x}_{a b 6}-\dot{x}_{a b 7}\right)
\end{aligned}
$$

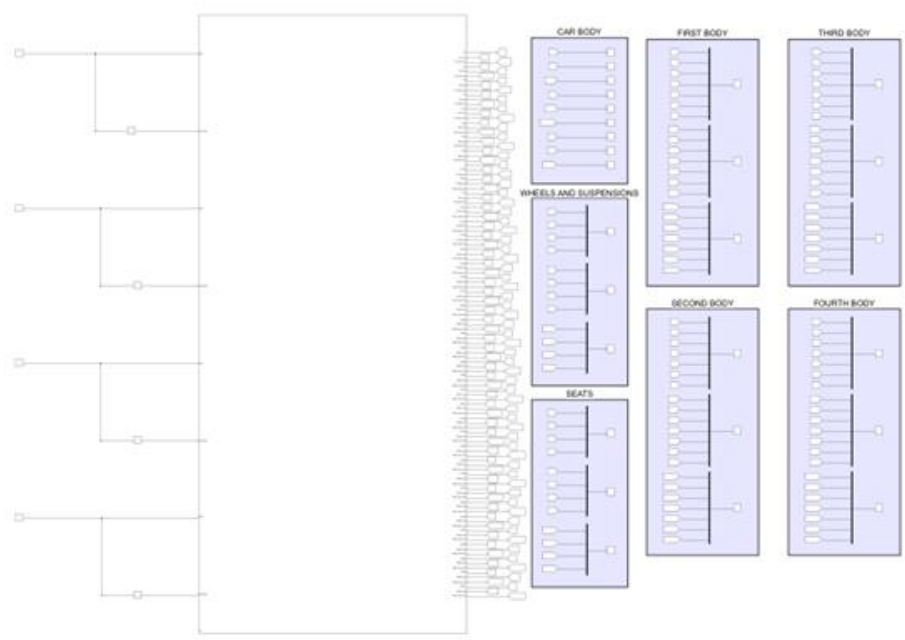

Figure 10 General view of Simulink model

Since the model has 39 degrees of freedom, there are 39 ordinary differential equations. In order to observe the dynamic

\begin{tabular}{|c|c|c|c|}
\hline \multicolumn{2}{|c|}{ Mass(kg) } & \multicolumn{2}{|c|}{ Spring Coeff. $(\mathrm{N} / \mathrm{m})$} \\
\hline $\mathrm{m}_{\text {body }}$ & 1506 & $\mathrm{k}_{1 \mathrm{t}}$ & 313767 \\
\hline $\mathrm{m}_{1}$ & 72 & $\mathrm{k}_{2 \mathrm{t}}$ & 313767 \\
\hline $\mathrm{m}_{2}$ & 72 & $k_{3 t}$ & 313767 \\
\hline $\mathrm{m}_{3}$ & 72 & $\mathrm{k}_{4 \mathrm{t}}$ & 313767 \\
\hline $\mathrm{m}_{4}$ & 72 & $\mathrm{k}_{1}$ & 30416 \\
\hline $\mathrm{m}_{1 \mathrm{~s}}$ & 90 & $\mathrm{k}_{2}$ & 30416 \\
\hline$m_{2 s}$ & 90 & $\mathrm{k}_{3}$ & 30416 \\
\hline $\mathrm{m}_{3 \mathrm{~s}}$ & 90 & $\mathrm{k}_{4}$ & 30416 \\
\hline $\mathrm{m}_{4 \mathrm{~s}}$ & 90 & $\mathrm{k}_{1 \mathrm{~s}}$ & 15000 \\
\hline \multicolumn{2}{|c|}{ Inertial Moments $\left(\mathrm{kgm}^{2}\right)$} & $\mathrm{k}_{2 \mathrm{~s}}$ & 15000 \\
\hline $\mathrm{I}_{\mathrm{xx}}$ & 2385 & $\mathrm{k}_{3 \mathrm{~s}}$ & 15000 \\
\hline$I_{Y Y}$ & 407 & $\mathrm{k}_{4 \mathrm{~s}}$ & 15000 \\
\hline \multicolumn{2}{|c|}{ Damping Coeff.(Ns/m) } & \multicolumn{2}{|c|}{ Dimensions(m) } \\
\hline $\mathrm{c}_{1 \mathrm{t}}$ & 150 & $\mathrm{~s}_{1 \mathrm{x}}$ & 0,45 \\
\hline $\mathrm{c}_{2 \mathrm{t}}$ & 150 & $\mathrm{~s}_{2 \mathrm{x}}$ & 0,45 \\
\hline$c_{3 t}$ & 150 & $s_{3 x}$ & 0,45 \\
\hline $\mathrm{C}_{4 \mathrm{t}}$ & 150 & $\mathrm{~S}_{4 \mathrm{x}}$ & 0,45 \\
\hline$c_{1}$ & 2500 & $\mathrm{~s}_{1 \mathrm{y}}$ & 1 \\
\hline$c_{2}$ & 2500 & $\mathrm{~S}_{2 y}$ & 1 \\
\hline$c_{3}$ & 2500 & $\mathrm{~S}_{3 y}$ & 1 \\
\hline $\mathrm{C}_{4}$ & 2500 & $\mathrm{~S}_{4 \mathrm{y}}$ & 1 \\
\hline $\mathrm{c}_{1 \mathrm{~s}}$ & 150 & $\mathrm{~d}_{1}$ & 2,128 \\
\hline$c_{2 s}$ & 150 & $\mathrm{~d}_{2}$ & 2,232 \\
\hline$c_{3 s}$ & 150 & $\mathrm{~L}_{1}$ & 0,911 \\
\hline $\mathrm{C}_{4 \mathrm{~s}}$ & 150 & $\mathrm{~L}_{2}$ & 0,911 \\
\hline
\end{tabular}
behaviour of the system, these 39 differential equations must be solved. In this study, a simulation study was carried out in Simulink environment due to its simplicity and prevalence for the solution of equations. At the same time, the same equations were solved numerically by writing a program in Python programming language to verify the results obtained using Simulink. The general view of the created Simulink model is given in Figure 10.

The model consists of 15 sub-models, including 4 wheels and suspension, 4 seats, 3 vehicle bodies $(\mathrm{x}, \theta, \varphi)$ and 4 human models (Figure 11).

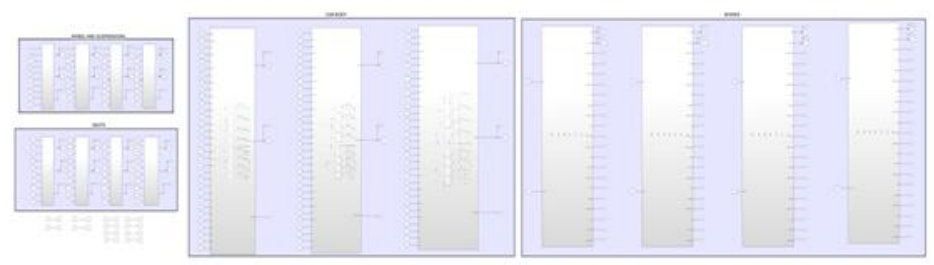

Figure 11 General view of sub-models

\section{Results}

An application has been made on the developed model. Before starting the application, it is necessary to determine some parameters in the model. The first of these is the geometrical and inertial properties of the vehicle to be used, as well as the spring and damping coefficients. In this application, the properties of an average passenger vehicle are used (Bowen L, 2019) (Table 1).

Table 1 Vehicle Parameters 
In addition, the mass, spring coefficient and damping coefficient values of the human model used should also be known. Linearized and optimized values of these parameters were used (Abbas, 2010) (Table 2).

Table 2 Parameters of 7 DOF human model

\begin{tabular}{|c|c|c|c|c|c|}
\hline \multicolumn{2}{|c|}{ Mass(kg) } & \multicolumn{2}{c|}{ Spring Coeff.(N/m) } & \multicolumn{2}{c|}{ Damping Coeff.(Ns/m) } \\
\hline Pelvis & 27,7 & $k_{a b 1}$ & 19325 & $C_{a b 1}$ & 463 \\
\hline Abdomen & 6,02 & $k_{a b 2}$ & 1035 & $C_{a b 2}$ & 225 \\
\hline Diaphragm & 0,4629 & $k_{a b 3}$ & 1052 & $C_{a b 3}$ & 354 \\
\hline Thorax & 1,389 & $k_{a b 4}$ & 845 & $C_{a b 4}$ & 237 \\
\hline Torso & 33,33 & $k_{a b 5}$ & 1001 & $C_{a b 5}$ & 351 \\
\hline Back & 6,94 & $k_{a b 6}$ & 40943 & $C_{a b 6}$ & 2685 \\
\hline Head & 5,55 & $k_{a b 7}$ & 39575 & $C_{a b 7}$ & 2929 \\
\hline & & $k_{a b 8}$ & 41978 & $C_{a b 8}$ & 3542 \\
\hline
\end{tabular}

In order to solve the differential equations of a vehicle with these features, a road profile input must be provided to the system. In the application, $0.3 \mathrm{~m}$ high step entrances were applied to a vehicle traveling at $20 \mathrm{~m} / \mathrm{s}$. Since the distance between the wheels is $4.36 \mathrm{~m}$, the time taken for the step input to reach the rear wheels is $4.36 / 20=0.218$ seconds. In this case, the road profile (step inputs) applied to the wheels is given in Figure 12.

39 ordinary differential equations are solved using the developed Simulink model under the above-mentioned conditions, at zero initial conditions, and for a solution interval of 25 seconds $(0-25 \mathrm{~s})$. In the figures below, the position, velocity and acceleration outputs obtained from the Simulink model are given (Figure 13).
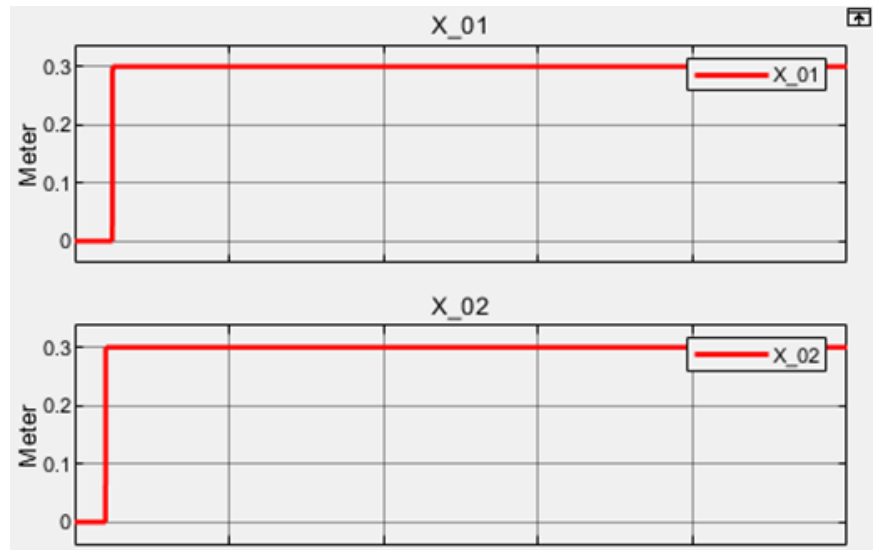

X_03
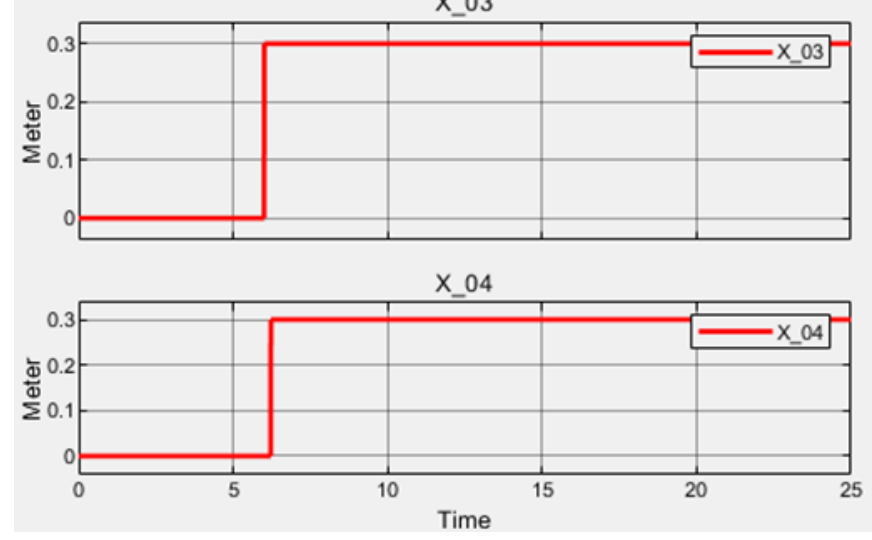

Figure 12 Road profiles
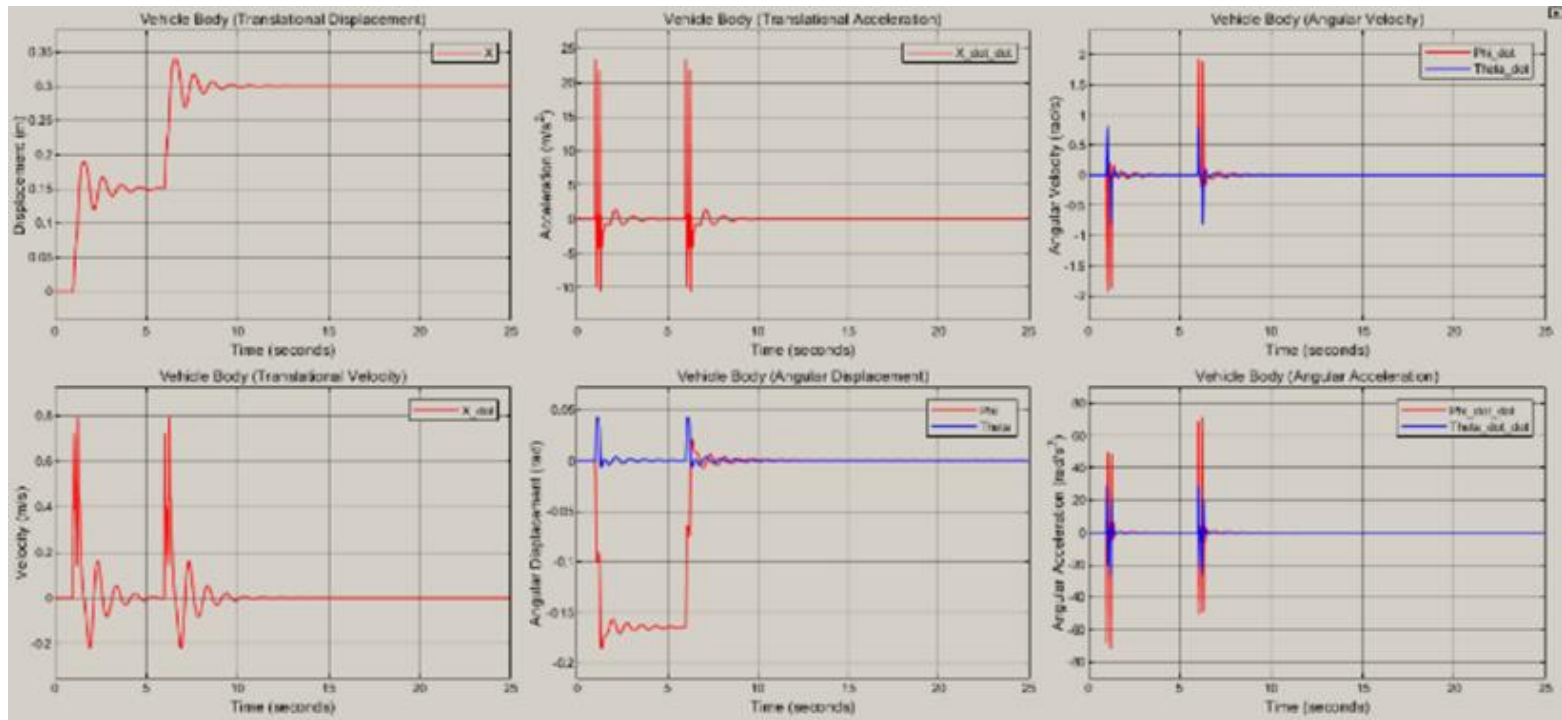

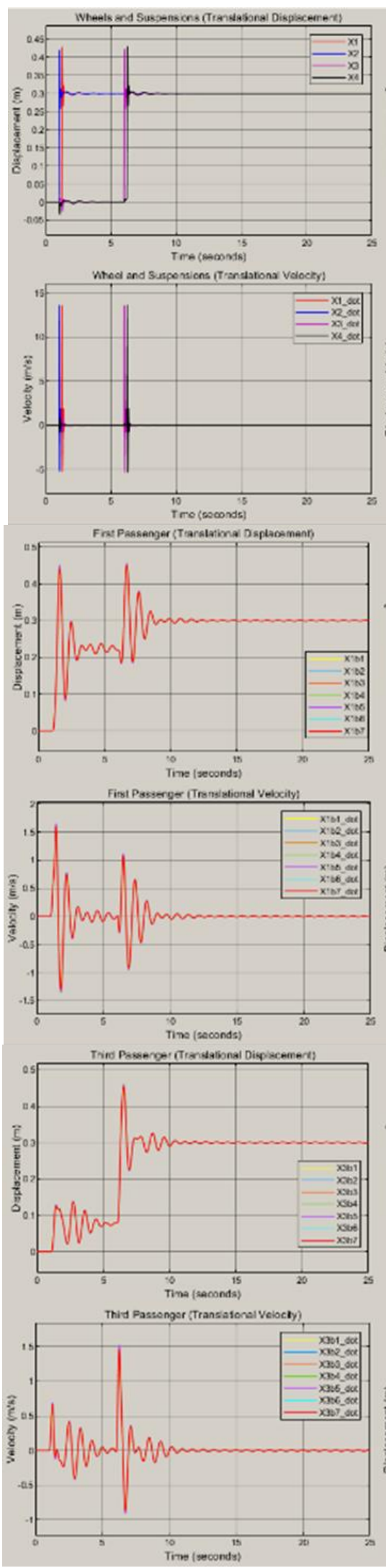

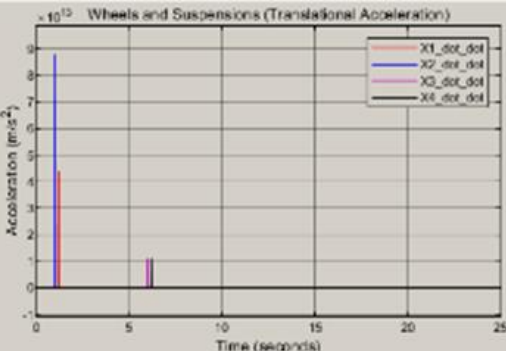

Tira (som seris)

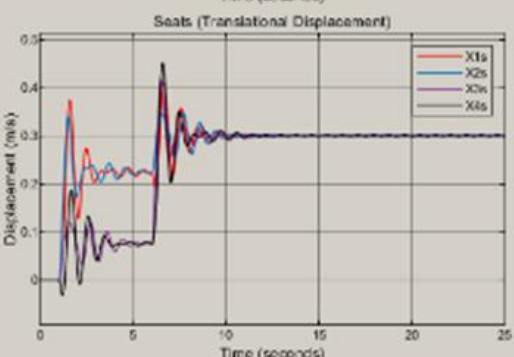

Fist Passenger (Tra nuational Acrectarsiton]

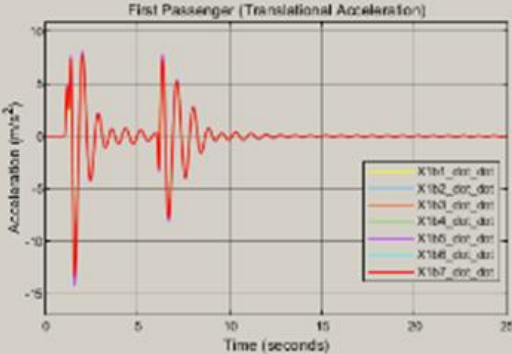

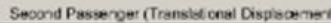
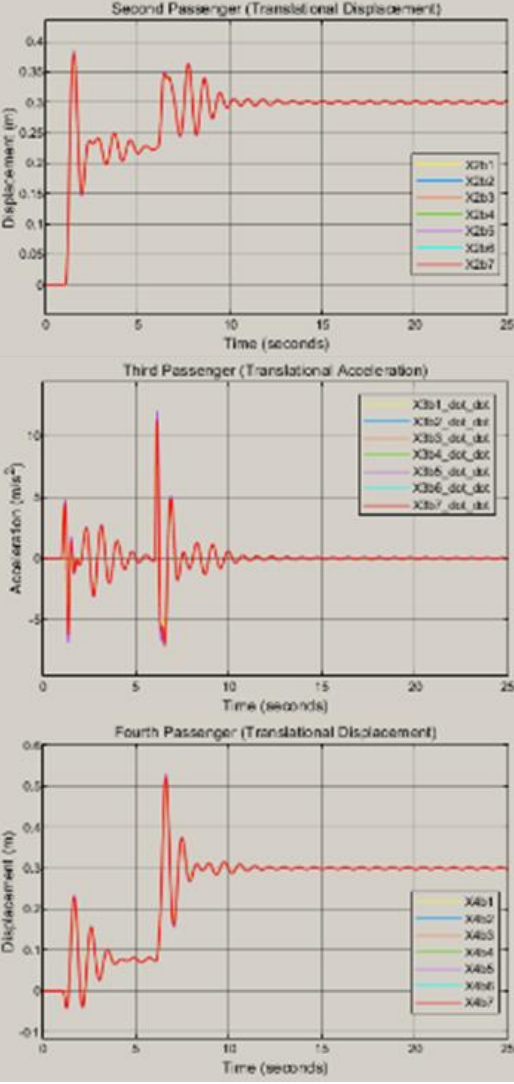

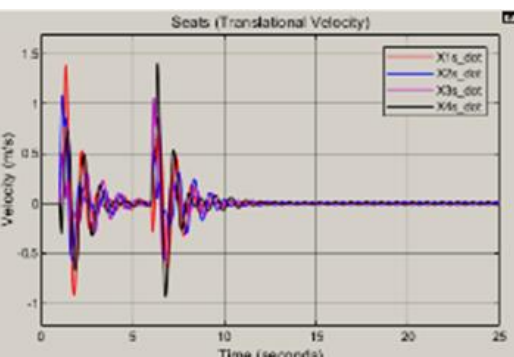

Soste (Tranelatona Accoloration)
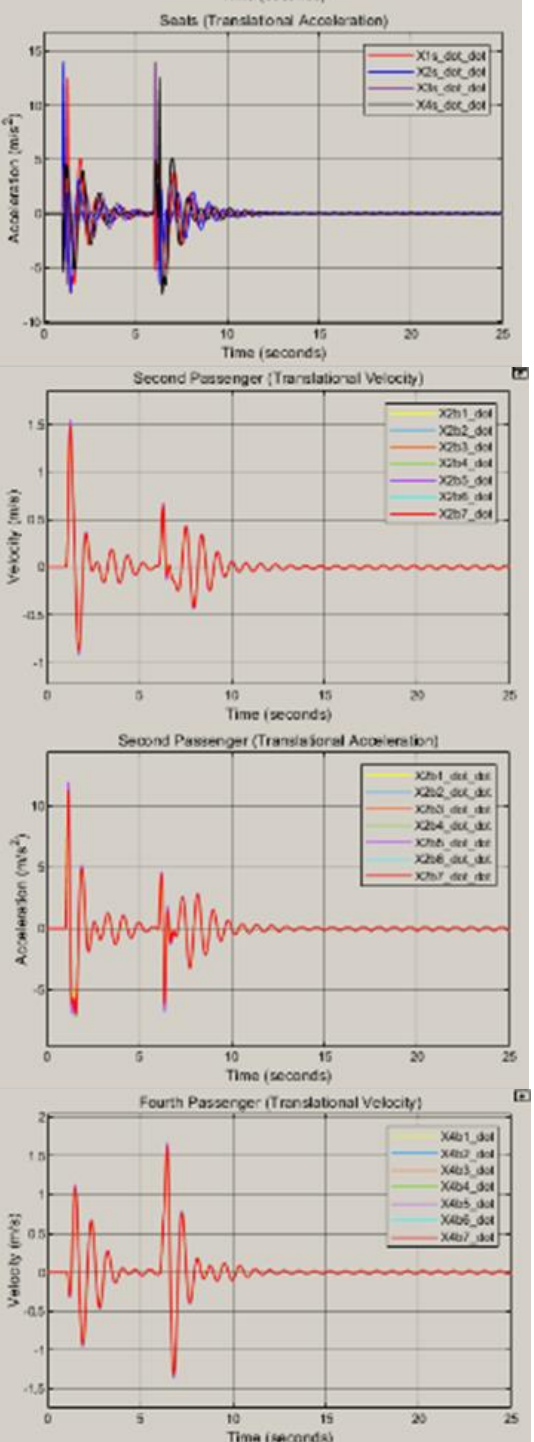

Fourth Pascongar (Translizend Acocleration)

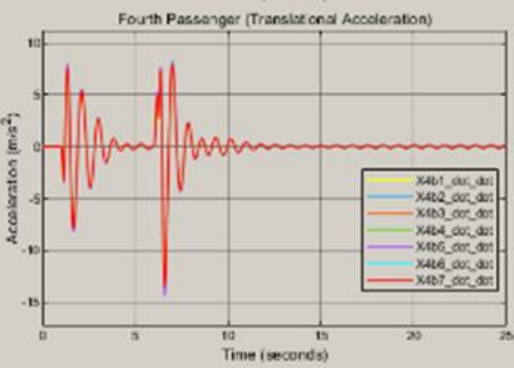

Figure 13 Outputs of Simulink model 


\section{Discussion and Conclusion}

In this study, a mass-spring-damper model with 39 degrees of freedom of a passenger car was created. The model created consists of 4 parts: wheels and suspensions, vehicle body, seats and passengers. A human model with 7 degrees of freedom was used to model the passengers. First, a free body diagram was drawn for each mass and the force and moment balance was written. Equations of motion were obtained by applying force and moment balances. A Simulink model was created to numerically solve the set of motion equations consisting of 39 differential equations. As an application, the equations of motion for the step input road profiles in which the vehicle moves at a speed of 20 $\mathrm{m} / \mathrm{s}$ are solved numerically using the Simulink model. The results obtained from the application were compared with the literature data and it was observed that the results were in harmony with the literature. Thanks to this study, the situations that affect passenger and driving comfort during vehicle design will be examined in a cheaper and more detailed way with less experimentation. In order for the mathematical model to give more realistic results, nonlinear spring and damper models should be used. In addition, rotational movements of only translational parts should be modeled.

\section{References}

Abbas, W. \&.-A. (2010). Optimization of Biodynamic Seated Human Models Using Genetic Algorithms. Engineering 02. doi:10.4236/eng.2010.29092

Bowen L, V. J. (2019). Design and Potential Power Recovery of Two Types of Energy Harvesting Shock Absorbers. Energies 12. doi:https://doi.org/10.3390/en12244710

Goga, V. \&. (2012). Optimization of Vehicle Suspension Parameters with use of Evolutionary Computation. Procedia Engineering 48, 174-179.

Hendrowati, W. (2012). Design, Modeling and Analysis of Implementing a Multilayer Piezoelectric Vibration Energy Harvesting Mechanism in the Vehicle Suspension. Engineering 04, 728-738.

Meng, R. \&. (2014). Multiobjective Game Method Based on SelfAdaptive Space Division of Design Variables and Its Application to Vehicle Suspension. Mathematical Problems in Engineering, 1-13.

Palanichamy, M. P. (1978). D.N. Minimization of the vertical vibrations sustained by a tractor operator, by provision of a standard-type tractor seat suspension. Ann Biomed Eng 6, 138-153. doi:https://doi.org/10.1007/BF02584540

Rao, S. S. (1993). Mechanical Vibrations. Mass: Addison-Wesley. 